\title{
Atividade fotossintética em plantas de ameixeira submetidas ao déficit hídrico e ao alagamento
}

\author{
Photosynthetic activity in japanese plum under water deficit and flooding
}

\author{
Emanuela Garbin Martinazzo ${ }^{\mathrm{I}}$ Anelise Tessari Perboni ${ }^{\mathrm{I}}$ Pablo Valadão de Oliveira ${ }^{\mathrm{I}}$ \\ Valmor João Bianchi' ${ }^{\mathrm{I}}$ Marcos Antonio Bacarin ${ }^{\text {I* }}$
}

\section{RESUMO}

O objetivo no presente trabalho foi avaliar o impacto do déficit hídrico e do alagamento na atividade fotossintética de ameixeiras cultivar 'América'. Foram analisadas a fluorescência da clorofila a e as trocas gasosas em plantas de aproximadamente 12 meses, cultivadas em casa de vegetação. As análises foram iniciadas dois dias após do início do déficit hídrico e um dia após o início do alagamento, totalizando quatro avaliações durante a manutenção dos estresses. A fotossíntese líquida foi reduzida pela limitação estomática em ambos os estresses. A condição de restrição hídrica não alterou o rendimento quântico máximo fotoquímico. Os índices de performance fotossintético revelaram diferenças entre os estresses, caracterizando as plantas de ameixeira, cv. 'América', como mais suscetíveis ao déficit hídrico do que ao alagamento.

Palavras-chave: Prunus salicina, fluorescência da clorofila a, teste JIP, trocas gasosas.

\section{ABSTRACT}

The objective of this study was to evaluate the impact of drought and flooding on the photosynthetic activity of Japanese plum (Prunus salicina Lindh), cultivar 'America'. We analyzed the chlorophyll fluorescence and leaf gas exchange in plants, with approximately 12 months, grown in greenhouse and subjected to water deficit. Analyses were initiated two days after the onset of drought and one day after the flooding, resulting in four evaluations during the maintenance of stress. Net photosynthesis was reduced by stomatal limitation in both stresses. The condition of water restriction did not alter the maximum quantum yield. The photosynthetic performance indexes showed differences between stresses, featuring the plants of plum $\mathrm{cv}$ America as the most susceptible to drought than flooding.

Key words: Prunus salicina, chlorophyll a fluorescence, JIP test, gas exchange.

\section{INTRODUÇÃO}

O estresse hídrico, considerado importante fator ambiental que compromete a fotossíntese, é um dos principais impedimentos do crescimento e produtividade das plantas. Estas respondem a esse estresse por meio de mecanismos adaptativos, permitindo que os sistemas fotoquímicos e bioquímicos, relacionados à fotossíntese, suportem situações adversas (OUKARROUM et al., 2007).

A capacidade fotossintética é progressivamente reduzida em condições de estresse hídrico, como consequência, menores intensidades luminosas são aproveitadas no processo fotossintético. Sob essas condições, as plantas não podem utilizar toda energia luminosa para a produção de ATP e NADPH , aumentando, dessa forma, a suscetibilidade à fotoinibiçã̃o (OUKARROUM et al., 2007). Vários estresses abióticos afetam, direta ou indiretamente, a capacidade fotossintética das folhas e, consequentemente, alteram a cinética da fluorescência da clorofila $a$ (OUKARROUM et al., 2007).

O déficit hídrico tem profundo impacto nos sistemas ecológicos e agrícolas, tendo em vista que as reações das plantas a esse estresse diferem em vários níveis de organização, dependendo da intensidade e da duração do estresse, bem como da espécie ou estádio de desenvolvimento (SHAO et al., 2008). O alagamento do solo confere restrições ao cultivo de muitas espécies pela falta de adaptação às condições

'Laboratório de Metabolismo Vegetal, Instituto de Biologia, Departamento de Botânica, Universidade Federal de Pelotas (UFPel), Campus Universitário, S/N, 96160-000, Capão do Leão, RS, Brasil. E-mail: bacarin@ufpel.edu.br. *Autor para correspondência. 
que solos hidromórficos apresentam, levando à baixa disponibilidade de oxigênio ao sistema radicular (DREW, 1997). O excesso de água no sistema radicular, em plantas terrestres, pode ser prejudicial ou mesmo letal, pois bloqueia a transferência de oxigênio e outros gases entre o solo e a atmosfera (DREW, 1997), devido à lenta difusão desse gás na água.

O gênero Prunus inclui espécies produtoras de frutos (a exemplo do pessegueiro, amendoeira, ameixeira, damasqueiro e cerejeira), entretanto várias são utilizadas como porta-enxertos e ornamentais. As ameixeiras são representadas por espécies com diferentes graus de ploidia, apresentando a maior diversidade taxonômica dentro das fruteiras de caroço e estão adaptadas a uma ampla gama de fatores climáticos e edáficos (ESMENJAUD et al., 2009), existindo assim diferenças marcantes de resposta entre as espécies a condições de estresse.

O sucesso do cultivo de espécies frutíferas de caroço na região sul do Brasil depende de alguns requisitos importantes, entre os quais, a utilização de mudas com qualidade garantida, materiais bem adaptados à região e de manejo adequado para obtenção de elevada produtividade do pomar. $\mathrm{Na}$ grande maioria dos anos, têm-se problemas devido ao estresse hídrico, em períodos críticos para a cultura, como é o caso da fase de florescimento (excesso de chuvas) e da fase que antecede a maturação dos frutos (déficit de pluviosidade), afetando a qualidade e a produtividade dos pomares.

A fluorescência da clorofila $a$ tem se tornado um método amplamente utilizado para avaliar as respostas das plantas aos estresses ambientais (STRASSER et al., 2000). É método não-invasivo, confiável, rápido e facilmente mensurável. Permite a obtenção de informações básicas sobre o estado do aparato fotossintético (CHRISTEN et al., 2007; THOREN et al., 2010), considerando aspectos funcionais e estruturais, principalmente do fotossistema II (FSII), bem como, tem sido método sensível para a detecção e quantificação das alterações induzidas no aparelho fotossintético (OUKARROUM et al., 2007). Através de medidas de fluorescência, tem sido possível caracterizar, quantificar e detectar o estresse de plantas antes que os sintomas se tornem visíveis nas folhas, especialmente sintomas relacionados ao estresse hídrico (CHRISTEN et al., 2007).

O objetivo neste trabalho foi avaliar o efeito do estresse provocado pelo déficit hídrico e pelo alagamento do solo na atividade fotossintética de plantas de ameixeira (Prunus salicina Lindh.) cultivar 'América', cultivadas em casa de vegetação.

\section{MATERIAL E MÉTODOS}

Mudas de ameixeira (Prunus salicina Lindh.), cultivar 'América', obtidas de reprodução assexuada por cultivo in vitro, disponibilizadas pelo Laboratório de Cultura de Tecidos de Plantas, da Universidade Federal de Pelotas, foram cultivadas em vasos de polietileno, com capacidade para 10L, contendo substrato Plantmax ${ }^{\circledR}$, sendo periodicamente irrigadas. Quinzenalmente, adicionou-se às plantas solução nutritiva de HOAGLAND \& ARNON (1950). As mudas foram mantidas em casa de vegetação modelo Double Poly Pad Fan. Quando as plantas apresentavam 12 meses, foi iniciado o experimento, que consistiu na indução do estresse hídrico, provocado pela suspensão da irrigação por um período de 11 dias (estresse por déficit hídrico), manutenção de lâmina d'água (aproximadamente $25 \mathrm{~mm}$ acima do nível do solo) por um período de 10 dias (estresse por alagamento) e um grupo de plantas controle, irrigadas diariamente. Foram avaliados os parâmetros de fluorescência da clorofila $a$ e de trocas gasosas, sendo repetidas em intervalos de três dias, iniciando-se no segundo dia após a retirada de água para o tratamento de déficit hídrico e, no primeiro dia após o alagamento das plantas, para o tratamento de alagamento.

As medidas de fluorescência da clorofila $a$ foram realizadas em folhas intactas, ligadas à planta $\mathrm{e}$ adaptadas ao escuro por 30 minutos. Foram utilizadas quatro folhas em cada planta, totalizando 12 medidas por tratamento. A fluorescência transiente da clorofila $a$ foi medida com o uso de um fluorômetro portátil (Handy-PEA, Hansatech Instruments Ltd., King's Lynn Norfolk, PE 30 4NE, UK). A fluorescência transiente foi induzida pela luz vermelha (pico em $650 \mathrm{~nm}$ ) de aproximadamente $3.000 \mathrm{mmol} \mathrm{m}^{-2} \mathrm{~s}^{-1}$. A intensidade da fluorescência medida a $50 \mu$ s foi considerada como fluorescência inicial.

A partir das intensidades de fluorescência da clorofila $a$, foram calculados os parâmetros propostos pelo teste JIP (STRASSER \& STRASSER, 1995; TSIMILLI-MICHAEL \& STRASSER, 2008), com a utilização do software Biolyzer (Laboratory of Bioenergetics, University of Geneva, Switzerland).

As trocas gasosas, sempre medidas entre 9 e $11 \mathrm{~h}$, foram efetuadas em folhas maduras, completamente expandidas, localizadas no terço médio de cada ramo, utilizando-se um analisador portátil a infra-vermelhode $\mathrm{CO}_{2}$ (modeloLI-6400XT, LI-COR, Inc., Lincoln, NE, USA). As leituras foram realizadas em três folhas por planta, totalizando nove folhas por tratamento, em cada coleta. As concentração de $\mathrm{CO}_{2}$ na câmara foram ajustados para $380 \mathrm{~mol} \mathrm{~mol}^{-1} \mathrm{e}$ 
densidade de fluxo de fótons de $1.200 \mu \mathrm{mol} \mathrm{m}^{-2} \mathrm{~s}^{-1}$, e a temperatura dentro da câmara manteve-se sempre em torno de $28^{\circ} \mathrm{C} \pm 2^{\circ} \mathrm{C}$.

O delineamento experimental utilizado foi $\mathrm{o}$ inteiramente casualisado com três tratamentos (controle, déficit hídrico e alagamento) e quatro coletas. Os parâmetros de trocas gasosas foram avaliados por meio da magnitude das médias e dos desvios padrão da média, utilizando-se três repetições e três leituras por plantas, totalizando nove determinações por tratamento. Foi realizada a análise de correlação de Pearson entre os valores de taxa de assimilação líquida e os índice de performance, utilizando-se, para tanto, o conjunto total de mensurações.

\section{RESULTADOS E DISCUSSÃO}

Na figura 1, são apresentados alguns parâmetros do Teste JIP em função do período dos estresses. Dentre os parâmetros que descrevem fluxos específicos por centro de reação (RC), verificou-se que o fluxo de absorção (ABS/RC), fluxo de energia capturado $\left(\mathrm{TR}_{0} / \mathrm{RC}\right)$ e o fluxo de dissipação de energia $\left(\mathrm{DI}_{0} / \mathrm{RC}\right)$ aumentaram, principalmente, aos 11 dias de déficit hídrico(Figura 1A), enquanto que, para as plantas sob alagamento (Figura 1B), esse aumento ocorreu aos 10 dias, sendo que neste estresse foi observado simultaneamente aumento do fluxo de transporte de elétrons $\left(\mathrm{ET}_{0} / \mathrm{RC}\right)$. $\mathrm{O}$ fluxo $\mathrm{DI}_{0} / \mathrm{RC}$ refere-se à perda de parte da energia absorvida pelo FSII, por meio de calor, emissão de fluorescência ou ainda, transferência de energia para outros sistemas (STRASSER et al., 2000). Tal relação pode ser decorrente da limitação da disponibilidade de $\mathrm{CO}_{2}$ para as reações bioquímicas da fotossíntese, as quais consomem o ATP e $\mathrm{NADPH}_{2}$. Dessa forma, a limitação estomática restringe a utilização dos adenilatos e do poder redutor, ocasionando regulação na cadeia de transporte de elétrons, de maneira a reduzir a produção desses compostos, ou são acionados mecanismos de regulação da absorção da energia pelos fotossistemas ou do fluxo de elétrons na cadeia de transporte de elétrons.

Os mecanismos de controle, associados ao aumento de $\mathrm{ABS} / \mathrm{RC}$ (estimativa do tamanho aparente do sistema coletor de luz do FSII por centro de reação decorrente), observado em ambos os estresse, foram, provavelmente: i. alteração no tamanho funcional do sistema antena do FSII; ii. alterações no número desses complexos; ou iii. inativação dos RC (centro de reação não redutor de $Q_{A}$ ) (EULLAFFROY et al., 2009). A inativação dos RCs pode ser uma indicação de suscetibilidade à fotoinibição, tendo em vista que o estresse diminuiu a taxa de fotossíntese, causada por um aumento na proporção de RCs inativos (TSIMILLIMICHAEL \& STRASSER, 2008).

$\mathrm{O}$ aumento em $\mathrm{TR}_{0} / \mathrm{RC}$ indica elevação do fluxo de energia capturado pelo RC, para as plantas submetidas a ambos os estresses, porém sob condições de restrição hídrica, ocorre aumento maior da energia dissipada por $\mathrm{RC}\left(\mathrm{DI}_{0} / \mathrm{RC}\right)$. Nas plantas sob alagamento, os fluxos por centro de reação acompanharam a cascata de energia, porém a queda no fluxo de redução de $Q_{A}$

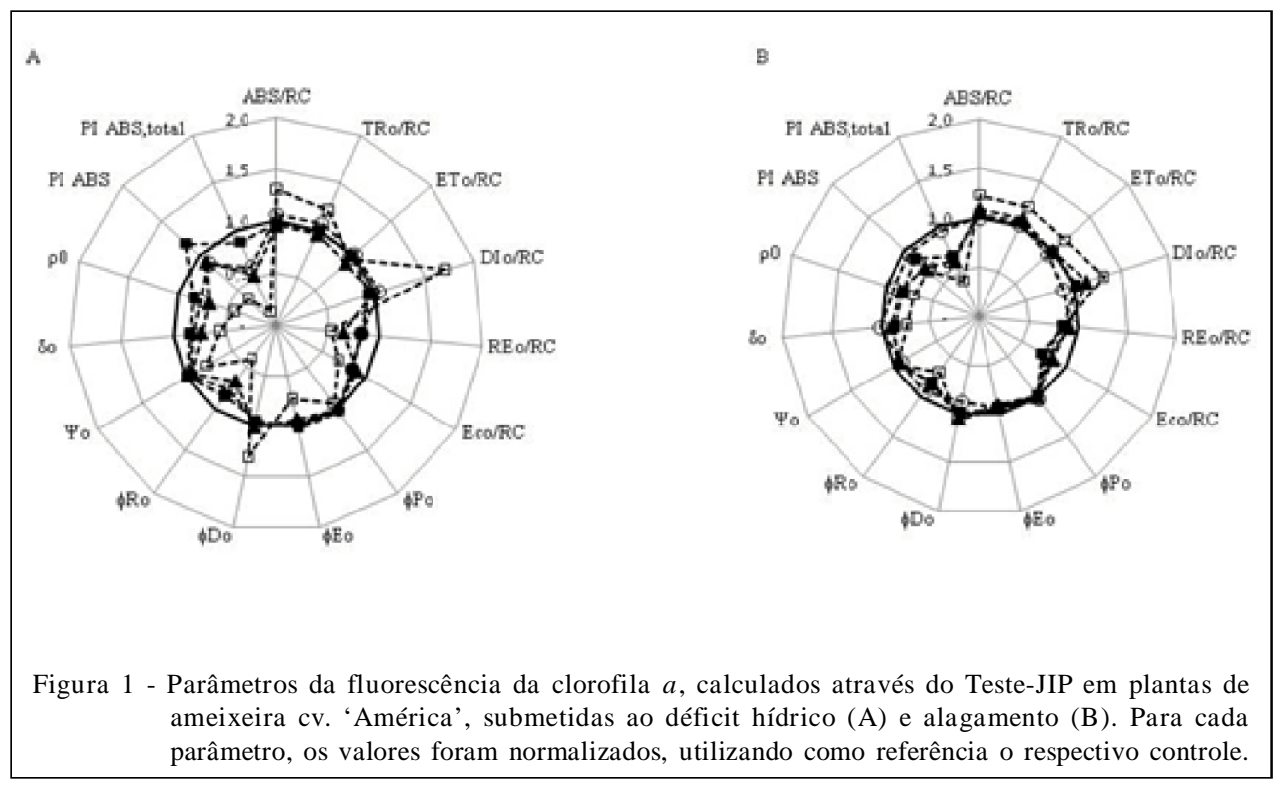

Ciência Rural, v.43, n.1, jan, 2013. 
pode ser explicada pela diminuição de transportadores de elétrons $\left(\mathrm{EC}_{0} / \mathrm{RC}\right)$, observada desde o primeiro dia de alagamento. Essa mudança pode estar associada também à alteração do número de complexos coletores de luz (LHC) por RC do FSII.

Para os parâmetros que descrevem o rendimento do fluxo energético, destaca-se o rendimento quântico fotoquímico máximo $\left(\varphi_{\mathrm{P} 0}\right)$, que não foi influenciado pelo tempo de estresse. $\mathrm{O}$ rendimento quântico máximo fotoquímico primário $\left(\varphi_{\mathrm{P} 0}=\mathrm{F}_{\mathrm{V}} / \mathrm{F}_{\mathrm{M}}\right)$ não é um indicador efetivo para situações de estresse provocadas pela restrição hídrica e pelo alagamento, tendo em vista que o rendimento permaneceu praticamente constante em relação ao controle, ao longo do período de estresse. Tal situação é descrita para variedades de Hordeum vulgare L., submetidas a condições de seca e posterior recuperação (OUKARROUM et al., 2007), em que os autores observaram uma ligeira diminuição do rendimento quântico máximo durante a seca. Da mesma forma, NAR et al. (2009) relatam que a não variação da razão $\mathrm{F}_{\mathrm{v}} / \mathrm{F}_{\mathrm{M}}$, durante o estresse aplicado, mostra que o rendimento quântico máximo fotoquímico permaneceu alto durante as condições de seca, sendo indicativo de que a cadeia de transporte de elétrons foi resistente à desidratação. Os resultados do presente trabalho reforçam as observações que $\mathrm{F}_{\mathrm{V}} / \mathrm{F}_{\mathrm{M}}\left(\varphi_{\mathrm{P} 0}\right)$ não é um indicador efetivo de estresse.

Contudo, aos 11 dias após o início do estresse por restrição hídrica, observou-se uma diminuição no rendimento quântico de transporte de elétrons $\left(\varphi_{\mathrm{E} 0}\right)$, com correspondente aumento no rendimento quântico para dissipação de energia $\left(\varphi_{\mathrm{D} 0}\right)$ (Figura 1A), situação não identificada para as plantas submetidas ao alagamento (Figura 1B).

Nas plantas submetidas aos dois estresses hídricos, houve redução acentuada e progressiva para o rendimento quântico de transporte de elétrons de $Q_{A}{ }^{-}$ para o aceptor de elétrons do fotossistema I - FSI ( $\left.\varphi_{\mathrm{R} 0}\right)$, porém o decréscimo foi muito mais intenso nas condições de déficit hídrico (Figura 1A). Os mesmos resultados foram observados para os parâmetros que descrevem a eficiência do fluxo energético envolvidos com a atividade do FSI $\left(\delta_{0}\right.$ - eficiência com que um elétron pode moverse do intersistema de aceptores de elétrons, reduzido para os aceptores finais do FSI e $\rho_{0}$ - eficiência com um éxciton capturado no centro de reação pode mover um elétron dentro da cadeia de transporte de elétrons de $\mathrm{Q}_{\mathrm{A}}{ }^{-}$para os aceptores finais do FSI). Porém, as maiores reduções foram observadas nas plantas submetidas ao déficit hídrico (Figura 1A), sendoo decréscimo crescente com o transcorrer de ambos os estresses.
$\mathrm{O}$ índice de performance $\left(\mathrm{PI}_{\mathrm{ABS}}\right)$ para as plantas mantidas sob déficit hídrico (Figura 1A) apresentou queda acentuada no $11^{\circ}$ dia após o início do estresse, enquanto, para aquelas sob alagamento, tal parâmetro manteve valores similares aos sete e 10 dias de estresse, porém a redução em $\mathrm{PI}_{\mathrm{ABS}}$, identificada para as plantas submetidas ao déficit hídrico, foi mais acentuada para aquela observada para as plantas alagadas. $\mathrm{O}$ índice de performance total $\left(\mathrm{PI}_{\mathrm{ABS}, \text { total }}\right)$, que descreve a operação em série dos dois fotossistemas, por meio do comportamento dos parâmetros estruturais do FSII até os aceptores finais de elétrons do FSI, reduziu, em relação ao controle, com o transcorrer do estresse por déficit hídrico (Figura 1A), atingindo os menores valores ao final do ensaio. Entretanto, para as plantas submetidas ao alagamento, observou-se diminuição no primeiro dia de estresse, seguido com o retorno para os valores do controle no quarto dia, com subsequente redução até o $10^{\circ}$ dia (Figura $1 \mathrm{~B}$ ). Tais resultados demonstram um efeito marcante dos estresses na atividade do FSI, sendo mais intensificada sob déficit hídrico.

Os índices de performance $\mathrm{PI}_{\mathrm{ABS}}, \mathrm{PI}_{\mathrm{ABS}, \text { total }}$ são parâmetros resultantes do produto de termos que expressam potenciais parciais para a conservação de energia a partir de um éxciton para a redução no intersistema de receptores de elétrons e para a redução dos aceptores finais de elétrons do FSI, respectivamente (TSIMILLI-MICHAEL \& STRASSER, 2008). Tais parâmetros são considerados os mais sensíveis a diferentes estresses, pois incorporam vários mecanismos que são avaliados a partir de transientes da fluorescência OJIP (TSIMILLIMICHAEL \& STRASSER, 2008). O leve aumento de $\mathrm{PI}_{\mathrm{ABS}}$ no início do estresse por alagamento pode ser interpretado como uma compensação por sua baixa capacidade fotossintética (OUKARROUM et al., 2007), de maneira a adaptar-se ao estresse inicial.

Na figura 2, são apresentados os dados dos parâmetros de trocas gasosas determinados durante $o$ transcorrer período de estresse. Sob condições de déficit hídrico, verificou redução na taxa assimilatória líquida do $\mathrm{CO}_{2}$ (A) (Figura 2A), sendo mais marcante após cinco dias de estresse, atingindo valores mínimos a partir do oitavo dia após o início da restrição hídrica. As plantas submetidas ao alagamento (Figura 2B) também apresentaram redução em $\mathrm{A}$, porém em intensidade menor do que o observado para as plantas com restrição hídrica (Figura $2 \mathrm{~A}$ ). Em relação à condutância estomática $(g s)$, observou-se pequena diferença entre os estresses, de forma que as plantas submetidas ao déficit hídrico induziram ao fechamento dos estômatos após oito dias de restrição hídrica 


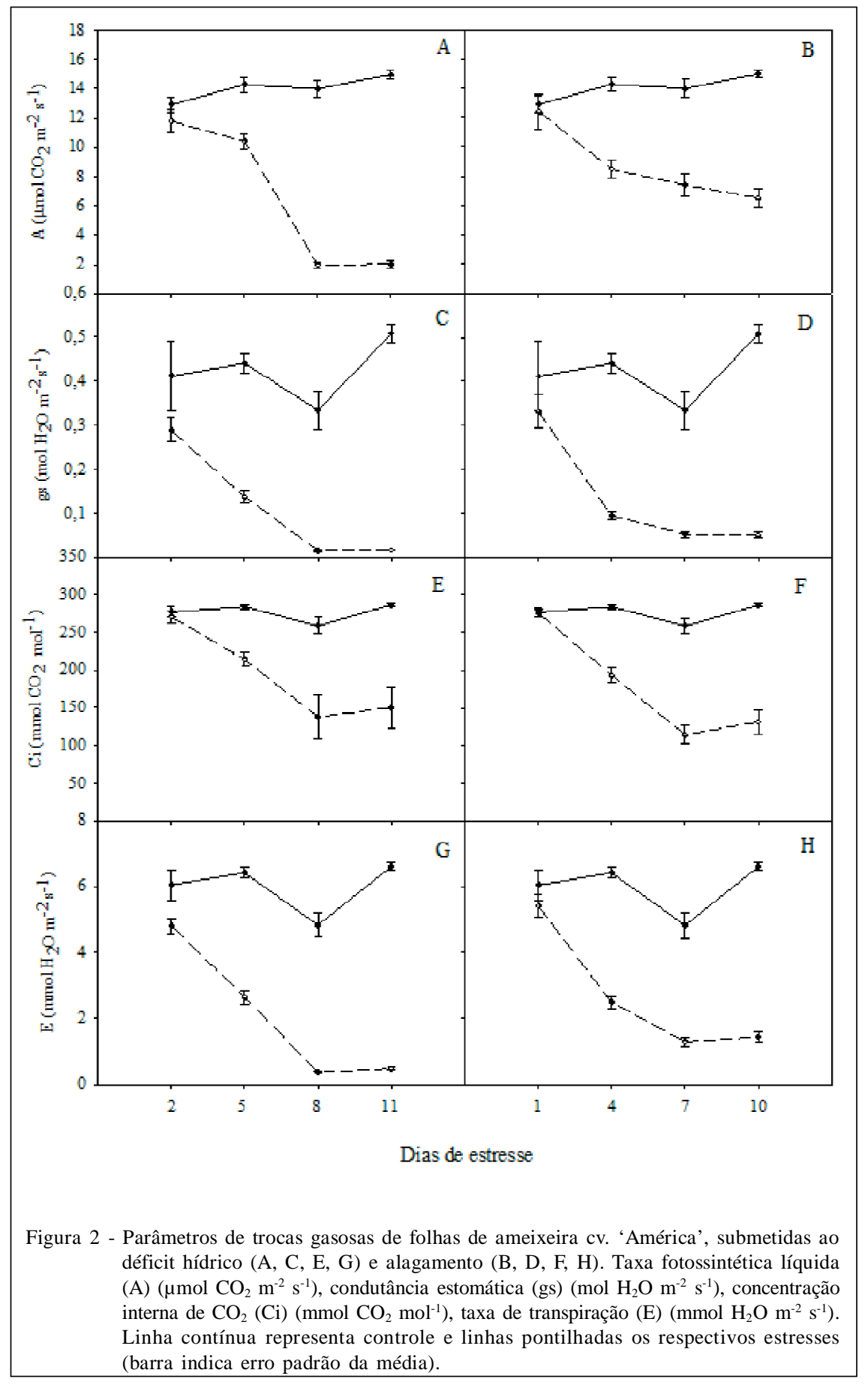

(Figura 2C), todavia, para o alagamento, os menores valores já foram observados a partir do quarto dia de estresse (Figura 2D). A concentração interna de $\mathrm{CO}_{2}$ (Ci) também reduziu com o decorrer dos estresses, contudo sem diferenciação de comportamento entre os estresses (Figuras 2E e 2F). A taxa transpiratória (E)
(Figuras $2 \mathrm{G}$ e $\mathrm{H}$ ) refletiu o que foi verificado para a condutância estomática.

Os resultados das trocas gasosas, observados no presente trabalho, corroboram as indicações de que a restrição hídrica no solo provoca decréscimo nos parâmetros relacionados às trocas 
gasosas nas folhas e, consequentemente, na taxa fotossintética líquida (CHARTZOULAKIS et al., 2002). Assim, esse declínio pode ser atribuído tanto à diminuição na condutância estomática, como em limitações não estomáticas quanto a alterações na funcionalidade do aparelho fotossintético, verificada pelas alterações na fluorescência da clorofila $a$. A redução nas taxas de assimilação de $\mathrm{CO}_{2}$ nas plantas de ameixeira, expostas aos estresses hídricos estudados, foi dependente do fechamento estomático, que diminuiu a disponibilidade interna de $\mathrm{CO}_{2}$ e restringiu a perda de água através da transpiração, além da redução em parâmetros de fluorescência da clorofila, associados principalmente ao FSI.

O fechamento estomático ajuda a manter o elevado teor de água nas folhas, o que resulta na redução da atividade fotossintética e transpiração (TEZARA et al., 2002). Contudo, há referências de que, sob estresse leve, um ligeiro declínio na condutância estomática pode ter efeito protetor, permitindo à planta economizar e melhorar a eficiência do uso da água (CHAVES et al., 2009) e, ainda, que os estômatos têm alta capacidade de adaptação às mudanças na disponibilidade de água (GRATANI \& GHIA 2002).

Em contrapartida, a diminuição na condutância estomática leva a uma diminuição na $\mathrm{Ci}$ de $\mathrm{CO}_{2}$ e na transpiração. A Ci de $\mathrm{CO}_{2}$ é um parâmetro que descreve a disponibilidade de dióxido de carbono para o processo fotossintético, sendo que a redução do $\mathrm{Ci}$ pode indicar a ocorrência das limitações dos estômatos (CHAVES et al., 2009), de forma que a resistência estomática e do mesofilo reduzem a concentração de $\mathrm{CO}_{2}$ que pode atingir os cloroplastos.

As avaliações da fluorescência da clorofila $a$, juntamente com trocas gasosas, possibilitaram o entendimento da atividade fotossintética das plantas de ameixeira nas condições impostas pelos estresses hídricos estudados. As menores taxas fotossintéticas foram observadas no transcorrer do tempo de déficit hídrico e alagamento, juntamente com o comprometimento dos fatores relacionados à atividade do FSII, a exemplo do aumento da dissipação de energia por centro de reação $\left(\mathrm{DI}_{0} / \mathrm{RC}\right)$ ao final do experimento, devido, provavelmente, ao fechamento estomático ocorrido ao oitavo e sétimo dias para o déficit hídrico e alagamento, respectivamente.

Visando a estabelecer se os índices de performance são correlacionados com a taxa assimilatória líquida, foi realizada a análise de correlação de Pearson entre todos os valores dos índices de performance com as respectivas taxas assimilatórias líquidas, independente do tratamento e época do estresse. Os resultados indicaram que a correlação entre $\mathrm{PI}_{\mathrm{ABS} \text {,total }} \mathrm{e}$ taxa assimilatória líquida foi positiva e altamente significativa $(r=0,60, P<0,01)$, da mesma forma para oPI e taxa fotossintética $(r=0,40, \mathrm{P}<0,01)$. Podendo, dessa forma, inferir que os PI são candidatos a indicadores positivos da atividade fotossintética, sendo que o $\mathrm{PI}_{\mathrm{ABS} \text {,total }}$ seria mais adequado, visto que este parâmetro engloba todas as etapas do fluxo energético na cadeia de transporte de elétrons da fotossíntese.

\section{CONCLUSÃO}

Plantas de ameixeira cv. 'América' apresentam redução na atividade fotossintética em resposta ao déficit e excesso de água no sistema radicular, porém são mais suscetíveis à restrição hídrica. Em ambos os estresses, a redução da fotossíntese líquida está associada à redução da condutância estomática e ao acréscimo no fluxo de dissipação por centro de reação $\left(\mathrm{DI}_{0} / \mathrm{RC}\right)$. A atividade do FSI é mais sensível a ambos os estresses, sendo mais afetada sob déficit hídrico. Existe uma correlação positiva entre a taxa de assimilação líquida de $\mathrm{CO}_{2}$ e o $\mathrm{PI}_{\mathrm{ABS} \text {,total }}$, sendo um parâmetro indicativo da taxa assimilatória líquida.

\section{AGRADECIMENTOS}

Ao Conselho Nacional de Desenvolvimento Científico e Tecnológico (CNPq), à Coordenação de Aperfeiçoamento Pessoal de Nível Superior (CAPES), ao Ministério de Ciência e Tecnologia e à Fundação de Amparo à Pesquisa do Rio Grande do Sul (FAPERGS), pelo apoio.

\section{REFERÊNCIAS}

CHARTZOULAKIS, K. et al. Water stress affects leaf anatomy, gas exchange, water relations and growth of two avocado cultivars. Scientia Horticulturae, Amsterdam, v.95, p.39-50, 2002. Disponível em: <http://dx.doi.org/S0304-4238(02)00016-X〉. Acesso em: 09 jun. 2011. doi: S0304-4238(02)00016-X.

CHAVES, M.M. et al. Photosynthesis under drought and salt stress: regulation mechanisms from whole plant to cell. Annals of Botany, London, v.103, p.551-560, 2009. Disponível em: <http://dx.doi.org/10.1093/aob/mcn125>. Acesso em: 15 jun. 2011. doi: $10.1093 / \mathrm{aob} / \mathrm{mcn} 125$.

CHRISTEN, D. et al. Characterization and early detection of grapevine (Vitis vinifera) stress responses to esca disease by in situ chlorophyll fluorescence and comparison with drought stress. Environmental and Experimental Botany, Elmsford, v.60, p.504-514, 2007. Disponível em: <http://dx.doi.org/ 10.1016/j.envexpbot.2007.02.003>. Acesso em: 17 jun. 2011. doi: $10.1016 /$ j.envexpbot.2007.02.003.

DREW, M.C. Oxigen deficiency and root metabolism: injury and acclimation under hypoxia and anoxia. Annual review of plant physiology and plant molecular biology, Palo Alto, v.48, p.223-250, 1997. Disponível em: <http://dx.doi.org/ 1040-2519/97/0601-0223>. Acesso em: 04 abr. 2011. doi: 1040-2519/97/0601-0223. 
ESMENJAUD, D. et al. Genetic dissection of resistance to rootknot nematodes Meloidogyne spp. in plum, peach, almond, and apricot from various segregating interspecific Prunus progenies. Tree Genetics \& Genomes, v.5, p.279-289, 2009. Disponível em: 〈http://dx.doi.org/10.1007/s11295-008-0173-x>. Acesso em: 02 fev. 2011. doi: 10.1007/s11295-008-0173-x.

EULLAFFROY, P. et al. Energy fluxes and driving forces for photosynthesis in Lemna minor exposed to herbicides. Aquatic Botany, Amsterdam, v.90, p.172-178, 2009. Disponível em: <http://dx.doi.org/10.1016/j.aquabot.2008.09.002>. Acesso em: 09 jun. 2011. doi: 10.1016/j.aquabot.2008.09.002.

GRATANI, L.; GHIA, E. Changes in morphological and physiological traits during leaf expansion of Arbutus unedo. Disponível em: <http://dx.doi.org/10.1016/S0098-8472(02)00010-2>. Acesso em: 13 maio, 2011. doi: 10.1016/S0098-8472(02)00010-2.

HOAGLAND, D.R; ARNON D.I. The water-culture method for growing plants without soil. California Agriculture Experimental Station Circular, v.347, p.1-32, 1950.

NAR, H. et al. Leaf rolling and photosystem II efficiency in Ctenanthe setosa exposed to drought stress. Photosynthetica, Prague, v.47, p.429-436, 2009. Disponível em: <http:// dx.doi.org/10.1007/s11099-009-0066-8>. Acesso em: 09 jun. 2011. doi: 10.1007/s1 1099-009-0066-8.

OUKARROUM, A. et al. Probing the responses of barley cultivars (Hordeum vulgare L.) by chlorophyll a fluorescence OLKJIP under drought stress and re-watering. Environmental and Experimental Botany, Elmsford, v.60, p.438-446, 2007. Disponível em: <http:/ /dx.doi.org/10.1016/j.envexpbot.2007.01.002>. Acesso em: 04 abr. 2011. doi: 10.1016/j.envexpbot.2007.01.002.
SHAO, H.B. et al. Water-deficit stress-induced anatomical changes in higher plants. Comptes Rendus Biologies, v.331, p.215-225, 2008. Disponível em: <http://dx.doi.org/10.1016/ j.crvi.2008.01.002>. Acesso em: 13 maio, 2011. doi: 10.1016/ j.crvi.2008.01.002.

STRASSER, B.J; STRASSER, R.J. Measuring fast fluorescence transients to address environmental questions: the JIP-test. In: MATHIS, P. (Ed.). Photosynthesis: from light to biosphere. The Netherlands: Kluwer Academic Publishers, 1995. p.977-980.

STRASSER, R.J. et al. The fluorescence transient as a tool to characterize and screen photosynthetic samples. In: YUNUS, M. et al. (Ed). Probing photosynthesis: mechanism, regulation and adaptation. London: Taylor \& Francis, 2000. p. $443-480$.

TEZARA, W. et al. Effects of water deficit and its interaction with CO supply on the biochemistry and physiology of photosynthesis in sunflower. Journal of Experimental Botany, Elmsford, v.53, p.1781-1791, 2002. Disponível em: <http://dx.doi.org/10.1093/jxb/erf021>. Acesso em: 09 jun. 2011. doi:10.1093/jxb/erf021.

THOREN, D. et al. Influence of ambient light and temperature on laser-induced chlorophyll fluorescence measurements. European Journal of Agronomy, v.32, p.169-176, 2010. Disponível em: <http://dx.doi.org/10.1016/j.eja.2009.10.003>. Acesso em: 13 maio, 2011. doi: 10.1016/j.eja.2009.10.003.

TSIMILLI-MICHAEL, M.; STRASSER, R.J. In vivo assessment of plants vitality: applications in detecting and evaluating the impact of Mycorrhization on host plants. In: VARMA, A. (Ed.). Mycorrhiza. Uttar Pradesh, India: Springer, 2008. p.679-703. 